\title{
Effects of acute hypoglycaemia on auditory information processing in adults with Type I diabetes
}

\author{
M. W. J. Strachan' ${ }^{2}$ F. M. E. Ewing 2 , B. M. Frier ${ }^{2}$, R. J. McCrimmon'2, I. J. Deary ${ }^{1}$ \\ ${ }^{1}$ Department of Psychology, Edinburgh, United Kingdom \\ ${ }^{2}$ Department of Diabetes, Royal Infirmary of Edinburgh, Scotland, United Kingdom
}

\section{Abstract}

Aims/hypothesis. Acute hypoglycaemia in humans causes general impairment of cognitive function, but information about its effects on more specific cognitive processes is limited.

Methods. Basic aspects of auditory function were studied in 15 adults with uncomplicated Type I (insulin-dependent) diabetes mellitus. Two separate hyper insulinaemic glucose clamp procedures were done on different study days, in a counterbalanced fashion, either maintaining euglycaemia (blood glucose $5.0 \mathrm{mmol} \cdot \mathrm{l}^{-1}$ ) or inducing hypoglycaemia (blood glucose $2.6 \mathrm{mmol} \cdot \mathrm{l}^{-1}$ ). During each study, the subjects performed a battery of auditory and cognitive function tasks.

Results. Hypoglycaemia caused deterioration in mental efficiency as assessed by Digit Symbol $(p<0.001)$ and Trail Making B $(p=0.004)$ tasks. Acute hypoglycaemia also caused deterioration in one of three measures of simple auditory processing (single-tone loudness, $p=0.001$ ) and in auditory temporal processing $(p=0.007)$. The amplitude and latency of auditory N100, P200 and P300 event-related potentials were not affected, but the amplitude of the N240 potential was reduced during acute hypoglycaemia.

Conclusion/interpretation. Our findings are consistent with other recognised disruptive effects of acute hypoglycaemia on sensory information processing in nondiabetic and diabetic adults, including adverse effects on auditory information processing in non-diabetic subjects. These derangements have implications for the everyday activities of people with Type I diabetes who are frequently exposed to acute hypoglycaemia. [Diabetologia (2003) 46:97-105]

Keywords Hypoglycaemia, cognition, auditory information processing, auditory event-related potentials, Type I diabetes mellitus.
People with Type I (insulin-dependent) diabetes mellitus are frequently exposed to episodes of acute hypoglycaemia. In experimental studies, a wide range of mental functions are impaired when arterialised blood

Received: 18 March 2002 / Revised: 19 June 2002

Published online: 23 November 2002

C) Springer-Verlag 2002

Corresponding author: I. J. Deary, Department of Psychology, 7 George Square, Edinburgh, United Kingdom, E-mail: I.Deary @ed.ac.uk

Abbreviations: AEP, Auditory evoked potential; AERP, Auditory event-related potential; TBAC, Test of Basic Auditory Capabilities; NART, National Adult Reading Test; AH4, Alice Heim 4; DAT, digital audio tape. glucose concentrations decline to between 2.4 and $2.8 \mathrm{mmol} \cdot \mathrm{l}^{-1}$ [1]. Cognitive functions that are affected include simple and choice reaction times, speed of arithmetical calculation, verbal fluency, attention and other indices of short-term memory [1]. The pattern of impairment of these tests allows a general interpretation of the nature of cognitive dysfunction during hypoglycaemia, but provides little information about the impact of hypoglycaemia on specific brain processes such as basic sensory information processing.

Two previous studies in our laboratory examined the ability of the brain to process visual information during acute hypoglycaemia. In one study [2] acute hypoglycaemia did not affect visual acuity or stereoscopic vision in non-diabetic subjects, but caused dis- 
ruption of early visual information processing as assessed by measures of visual inspection time, simple visual discrimination and the ability to detect the locus of a discrete change of movement. These findings were mainly replicated in a subsequent study of adults with Type I diabetes [3].

In contrast to visual processing, the effects of acute hypoglycaemia on core aspects of auditory information processing have received little attention. In one study in non-diabetic humans [4], hypoglycaemia provoked deterioration in auditory temporal processing and in one of three tasks of simple auditory processing (the ability to detect the louder of two tones).

Electrophysiological techniques, such as auditory evoked potentials (AEPs) and auditory event-related potentials (AERPs), have been used to examine the effect of acute hypoglycaemia on auditory information processing. AEPs are recorded over the scalp during the onset and subsequent processing of an auditory stimulus, such as repetitive clicks of a given frequency and volume. Two studies, using AEP techniques, have suggested that conduction through brain-stem structures involved in the auditory pathway was impaired during acute hypoglycaemia in non-diabetic and diabetic subjects $[5,6]$. In two other studies, however, brain-stem AEPs were not altered by acute hypoglycaemia in adult subjects who had Type I diabetes with strict glycaemic control $[7,8]$ and in non-diabetic volunteers [7].

AERPs reflect cognitive processing of an auditory stimulus. The auditory cognitive task that is most commonly applied is an 'odd-ball' task in which subjects are presented with frequent and infrequent targets (such as tones of two different frequencies) and are asked to count the number of occasions on which the infrequent targets are presented [9]. A variety of different components of AERPs can be measured; the most commonly assessed is the P300 wave (i.e. a positivity occurring at approximately $300 \mathrm{msec}$ after the 'odd-ball' stimulus presentation, but which is absent after the more frequent stimulus is presented). The latency of the peak P300 waveform correlates with psychometric intelligence scores in some studies and is thought to relate to the cognitive processes of stimulus evaluation [9]. Most, but not all studies [10, 11], in non-diabetic subjects have suggested that the latency of auditory P300 peak is prolonged during acute hypoglycaemia $[5,12,13,14,15,16]$; a reduction in the amplitude of the auditory P300 component has also been reported [5, 14].

In people with Type I diabetes, data on the effects of acute hypoglycaemia on AERPs are much more limited and, to our knowledge, there are no data on the effects of hypoglycaemia on psychophysical auditory decision-making tests. It might not be possible to extrapolate the results of previous studies of non-diabetic subjects, since people with insulin-treated diabetes are exposed to wide fluctuations in blood glucose con- centrations, with intermittent exposure to acute hypoglycaemia which can modify glycaemic thresholds for cognitive dysfunction $[17,18]$. Basic aspects of auditory processing are, however, of crucial importance for the development of hearing and language. The aims of our study were, therefore, to examine the effects of acute hypoglycaemia on fundamental aspects of auditory information processing in subjects with Type I diabetes, as assessed by psychophysical tests and AERPs.

\section{Subjects and methods}

Subjects. Fifteen adults (11 men, 4 women) with Type I diabetes were recruited from the diabetes out-patient clinic at the Royal Infirmary of Edinburgh. None had any other relevant previous medical history, nor were they taking any regular medication other than insulin. None of the subjects had evidence of overt microvascular and macrovascular complications of diabetes. All subjects had a corrected visual acuity of $6 / 6$ or better, as measured with a Snellen chart, and none reported a hearing disorder. All subjects reported having normal perception of the onset of symptoms of hypoglycaemia (awareness of hypoglycaemia) and none had a history of severe hypoglycaemia in the preceding 6 months. The mean age $( \pm$ SD) was 26.5 $( \pm 9.1)$ years, the mean duration of diabetes $( \pm$ SD) was 11.1 $( \pm 6.6)$ years and the mean BMI $\left( \pm\right.$ SD) was $22.9( \pm 1.7) \mathrm{kgm}^{-2}$. At recruitment, glycated haemoglobin $\left(\mathrm{HbA}_{1 \mathrm{c}}\right)$ was measured using high-speed liquid chromatography based on an ionexchange, reverse-phase partition method (Hi Auto A1c HA 8121). The mean $\mathrm{HbA}_{1 \mathrm{c}}( \pm \mathrm{SD})$ was $8.8( \pm 2.0) \%$; the local non-diabetic range was 5.0 to $6.5 \%$.

General intellectual ability was assessed before the glucose clamp studies by the National Adult Reading Test (NART) [19] and the Alice Heim 4 Test (AH4) [20]. The mean ( \pm SD) NART error score was $15.2( \pm 5.5)$, and the mean $( \pm$ SD) AH4 score was $88.5( \pm 11.3)$, indicating that subjects had above average intelligence. Written informed consent was obtained from all subjects and the study was approved by the Lothian Medical Ethics Advisory Committee.

Experimental procedure. Subjects attended three study sessions, each separated by at least 2 weeks. The purpose of the initial visit was to familiarise subjects with the tests that would be used in the experimental sessions, so as to reduce the effects of practice on test results. The results from this session were not analysed. In the following two study sessions, the participants underwent the experimental procedures during conditions of either hypoglycaemia or euglycaemia. The subjects were not informed which condition was being studied at each visit, nor were they informed about their blood glucose concentration during any phase of the study. They completed both experimental conditions in a counterbalanced fashion, i.e. eight of the subjects underwent the euglycaemia study first followed by the hypoglycaemia study and the other seven underwent the studies in the reverse order.

All subjects were asked to measure their blood glucose concentrations frequently for 5 days before each experimental session and to avoid exposure to symptomatic or biochemical (blood glucose $<3.5 \mathrm{mmol} \cdot \mathrm{l}^{-1}$ ) hypoglycaemia. If they experienced any hypoglycaemia during these phases of the study, the test procedure was postponed for a further 5 days. During the two experimental visits, subjects underwent a glucose clamp procedure. 
After a light breakfast at 07.00 hours, the subjects were asked to attend the department at midday. To avoid any preceding nocturnal hypoglycaemia or a low blood glucose on the morning of the experimental study, the subjects were instructed to reduce their dose of isophane insulin by $33 \%$ on the day before the study, to take half their normal dose of short-acting (soluble) insulin before breakfast and to omit any morning dose of isophane insulin. A teflon cannula was inserted into an antecubital vein in the subject's non-dominant arm under local anaesthetic (1\% lignocaine). This cannula was used to infuse human soluble insulin (Actrapid, Novo Nordisk Pharmaceuticals, Crawley, UK) and $20 \%$ dextrose. A second cannula was inserted in a retrograde direction into a vein on the dorsum of the same hand, which was then placed in a heated box (Plexiglass) at $60^{\circ} \mathrm{C}$ to arterialize the venous blood. Arterialised blood samples were obtained throughout the study for the measurement of whole blood glucose at the bedside using a glucose oxidase method (Yellow Springs Instrument 2300 Stat, Yellow Springs, Ohio, USA). To maintain patency, both cannulae were flushed frequently with heparinised saline.

Where appropriate, insulin was infused at a rate of 2 to 6 units per hour to lower the blood glucose to approximately $5.0 \mathrm{mmol} \cdot \mathrm{l}^{-1}$. Following this, a modified hyperinsulinaemic glucose clamp technique was used to maintain the blood glucose at predetermined concentrations [21]. Insulin was infused at a steady rate (based on whole-body surface area) of $60 \mathrm{mU}$ $\mathrm{m}^{-2} \cdot \mathrm{min}^{-1}$ using an IMED Gemini PC1 pump; $20 \%$ dextrose was infused, using an IVAC Site Saver pump, at a variable rate according to the blood glucose value. Arterialised blood glucose was measured initially every three min, until a stable concentration had been achieved, and then at 5 min intervals. Plasma concentrations of counter-regulatory hormones were not estimated.

At each laboratory session, the arterialised blood glucose concentration was initially stabilised at $5.0 \mathrm{mmol} \cdot \mathrm{l}^{-1}$ for 50 min during which the subject completed the test battery (baseline). The blood glucose concentration was then either maintained at $5.0 \mathrm{mmol} \cdot \mathrm{l}^{-1}$ (euglycaemia) or lowered to $2.6 \mathrm{mmol} \cdot \mathrm{l}^{-1}$ (hypoglycaemia) and maintained at this concentration for $50 \mathrm{~min}$, during which the test battery was repeated. A period of 20 min elapsed from baseline until euglycaemia or hypoglycaemia was attained to allow stabilisation of the target blood glucose concentration, which was maintained for a further 10 min before the tests were administered.

Cognitive test battery. A specialised psychological and auditory psychophysical test battery was applied during the baseline and experimental phases of the euglycaemia and hypoglycaemia conditions. The tests were administered in the order presented below, which was maintained during each phase of the visit. Symptoms of hypoglycaemia were measured at the end of each phase using the Edinburgh Hypoglycaemia Scale [22].

Two complex psychometric tests of mental efficiency, which are known to be sensitive to moderate hypoglycaemia $[2,3,4]$, were used to assess high-level cognitive function.

Digit Symbol task. This is a sub-test of the Wechsler Adult Intelligence Scale - Revised (WAIS-R) [23]. In the task, nine digits are represented by nine different symbols, and the subject is required to write down the appropriate symbol for each in a given array of numbers over $90 \mathrm{~s}$. The number of correct responses is recorded.

Trail-Making Test B. This is a test from the Halstead Reitan Neuropsychological Battery [24]. The subject has to connect correctly an alternating series of numbers (1-13) and letters (A-L) in their respective orders as quickly as possible. The time (in seconds) taken to complete the task correctly is recorded.
Tests of auditory information processing. Simple auditory processing and auditory temporal processing were assessed using tests from the Boys Town Institute Test of Basic Auditory Capabilities (TBAC) [25]. As its name suggests, this battery of auditory decision-making tests was developed by psychophysicists to assess fundamental aspects of auditory information processing. The tests were recorded on digital audio tape together with detailed instructions for the subjects. A standard comparator stimulus preceded the two stimuli of a two-alternative, forced-choice presentation, yielding three stimuli in total for each item. The subject's task was to identify which of the two stimuli differed from the standard comparator. This psychophysical procedure thus involved only two types of trials SDS and SSD (S, standard stimulus and D, different stimulus). The subject's task was to identify D. This method minimised demands on attention and memory, while providing a valid test of auditory processing abilities [26]. Trials were presented in a series of six steps of the independent variable, in ascending difficulty. A total of 72 trials were used for each sub-test. The stimulus tones were all gated with $5 \mathrm{msec}$ rise-decay times to minimise onset and offset transients.

The studies were carried out in a sound-controlled listening room with an ambient sound level of 30 to $32 \mathrm{~dB}$. The TBAC was recorded on digital audio tape (DAT) and played to the subjects on a Sony DAT recorder. Subjects listened to the tests with Beyer DT 100 headphones. The tasks were done at a sound level of $67 \mathrm{~dB}$ (mean of 10 recordings using a regularly calibrated Castle Associates Sound Level Meter).

Four of eight subsets of the TBAC were used to assess simple auditory processing (pitch discrimination, single-tone loudness, single-tone duration) and non-verbal auditory temporal processing (temporal order discrimination) [27].

The standard for pitch discrimination was a $1 \mathrm{khz}, 75 \mathrm{~dB}$ SPL, $25 \mathrm{msec}$ tone. The values of the frequency differences ranged from 2-256 Hz.

The standard for single-tone loudness was a $1 \mathrm{khz}, 75 \mathrm{~dB}$ SPL, $250 \mathrm{msec}$ tone (increments in level ranged from 0.5-8.0 dB).

The standard for single-tone duration was a $1 \mathrm{khz}, 100 \mathrm{~dB}$ $\mathrm{SPL}, 250 \mathrm{msec}$ tone (increments in duration ranged from 8-256 msec).

For temporal order discrimination the subjects had to discriminate the order in which two tones (one of $550 \mathrm{~Hz}$, the other of $710 \mathrm{~Hz}$ ) were presented. The duration of the two tones was varied from 20 to $200 \mathrm{msec}$. The tones were presented without a gap between them and were preceded and followed, without gaps, by $100 \mathrm{msec}, 625 \mathrm{~Hz}$ 'leader' and 'trailer' tones.

The TBAC was designed to yield overall percentage scores of 75 to $90 \%$ in young adults with normal hearing [26].

Auditory event-related potentials. An 'odd-ball' procedure was used to elicit auditory event-related potentials (AERPs). Stimuli were generated and presented, and AERPs collected and analysed, by the Biologic Brain Atlas system. Two tones (a $1000 \mathrm{~Hz}$ non-target tone and a $250 \mathrm{~Hz}$ target, 'odd-ball' tone) were delivered biaurally through headphones at $60 \mathrm{~dB}$, at a rate of 0.9 per second. Participants were asked to ignore the nontarget tones, and count the target, 'odd-ball' tones which were presented at random with a probability of 0.25 . The minimum number of target tones was set at 50. The AERPs were recorded over an epoch of 1024 milliseconds at three standard electrode sites, based on the International 10 to 20 system [28]: Fz, $\mathrm{Pz}$ and $\mathrm{Cz}$. The AERPs were referred to the left and right preauricular points, with the nasion earthed, and the impedance of each channel was below $5 \mathrm{~K} \Omega$. The AERP waveforms from the 'odd-ball' stimuli were recorded and averaged to produce a single AERP for each site. 
The characteristic trace of the 'oddball' paradigm consists of negative troughs at approximately $100 \mathrm{msec}(\mathrm{N} 100)$ and $240 \mathrm{msec}$ (N240), and positive peaks at approximately $200 \mathrm{msec}$ (P200) and $300 \mathrm{msec}$ (P300) [9]. The N100 wave was defined as the most negative potential within the latency range 50 to $140 \mathrm{msec}$. The $\mathrm{P} 200$ and $\mathrm{P} 300$ waves were defined, respectively, as the most positive potentials within the 140 to $250 \mathrm{msec}$ and 250 to $500 \mathrm{msec}$ latency ranges. The N240 wave was defined as the most negative potential occurring between the P200 and P300 waves. The latency and amplitude of each wave was recorded during the study conditions of euglycaemia and hypoglycaemia. Grand average AERPs were also generated by combining the AERP data obtained from all 15 subjects.

Edinburgh hypoglycaemia scale. This is a validated, subjective self-rating system [22], using a Likert scale, in which subjects are presented with a list of symptoms of hypoglycaemia and are asked to score the magnitude of intensity of each symptom from 1 (not present) to 7 (very intense). Symptom scores were totalled and classified into three groups: autonomic, neuroglycopenic and non-specific.

Statistical analyses. All experimental data are presented as means \pm SD. Each measure of auditory information processing, cognitive function and symptoms was analysed independently.

To control for day-to-day variation in cognitive performance and symptoms of hypoglycaemia, the results of the cognitive tasks and the symptom questionnaire during the study condition were adjusted for baseline scores (on the day of the relevant study condition) using linear regression. The effects of hypoglycaemia on cognitive and symptom parameters were then investigated by comparing the standardised residuals of the study results during euglycaemia and hypoglycaemia conditions using a mixed-model Analysis of Variance (ANOVA). 'Order of session' was used as a between-subjects factor with two levels (euglycaemia-hypoglycaemia or hypoglycaemia-euglycaemia). The within-subjects factor, 'experimental condition', had two levels, euglycaemia versus hypoglycaemia. A similar mixedmodel ANOVA was used to compare the latencies and ampli- tudes of the N100, P200, N240 and P300 waves during the study conditions of euglycaemia and hypoglycaemia, except that actual study condition results, rather than residuals, were used.

Baseline blood glucose concentrations were compared using a paired Student's $t$ test. In all analyses, a $p$ value of less than 0.05 was considered to be significant. All analyses were carried out using SPSS version 10.0 for Windows 2000 .

\section{Results}

Glucose clamps. Mean arterialised blood glucose concentration at the start of the euglycaemia study day was $8.70 \pm 5.32 \mathrm{mmol} \cdot \mathrm{l}^{-1}$ and at the start of the hypoglycaemia study day was $9.35 \pm 3.22 \mathrm{mmol} \cdot \mathrm{l}^{-1} \quad(p=0.619)$. Stable glycaemic plateaux were achieved for every subject in each condition of the study. The arterialised blood glucose concentrations during both baseline euglycaemic clamps were $5.01 \pm 0.32 \mathrm{mmol} \cdot \mathrm{l}^{-1}$. During the experimental conditions of euglycaemia and hypoglycaemia, blood glucose concentrations were $5.00 \pm$ $0.26 \mathrm{mmol} \cdot \mathrm{l}^{-1}$ and $2.59 \pm 0.18 \mathrm{mmol} \cdot \mathrm{l}^{-1}$ respectively.

Effects of order. No effects of order were observed on any of the outcome variables, with the exception of N240 amplitudes and N100 latencies. Combining the study data from both the euglycaemia and hypoglycaemia clamps, the N240 amplitudes in subjects who first underwent the euglycaemic clamp were $6.5 \pm 3.4 \mathrm{uv}$ and $4.2 \pm 3.4 \mathrm{uv}$ at the $\mathrm{Cz}$ and $\mathrm{Pz}$ electrodes respectively, but were lower at $1.7 \pm 2.6 \mathrm{uv}(p=0.004)$ and $2.1 \pm 4.6$ uv $(p=0.006)$ respectively in subjects who first underwent the hypoglycaemic clamp. Similarly, the N100 latencies in subjects who first underwent the euglycaemic clamp were $98.3 \pm 9.1 \mathrm{msec}$ and

Table 1. Results of cognitive function tests, auditory information processing tests and symptom scores during euglycaemia and hypoglycaemia

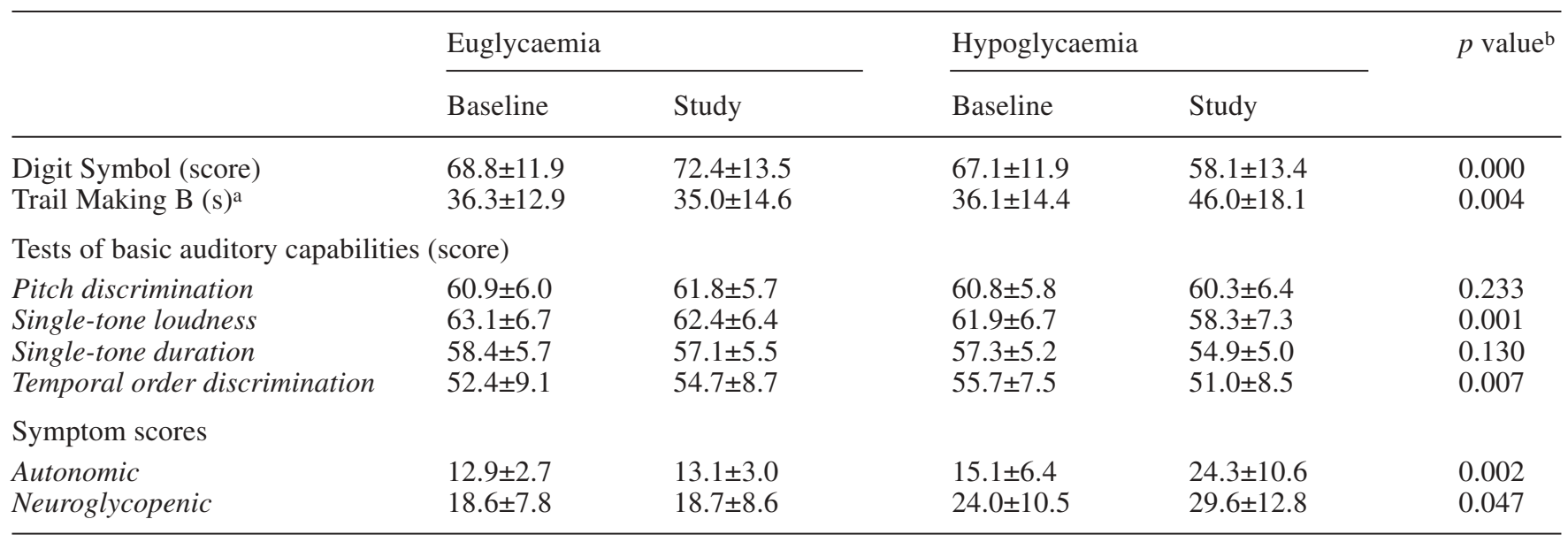

a In the Trail Making B task, a lower score represents better performance; in all other cognitive and auditory tasks, a higher score indicates better performance

${ }^{\mathrm{b}} p$ values refer to the comparison between the study scores obtained during euglycaemia and hypoglycaemia, after adjustment for baseline scores
Results are presented from the baseline and study conditions of the euglycaemia and hypoglycaemia study days Values are means \pm SD 

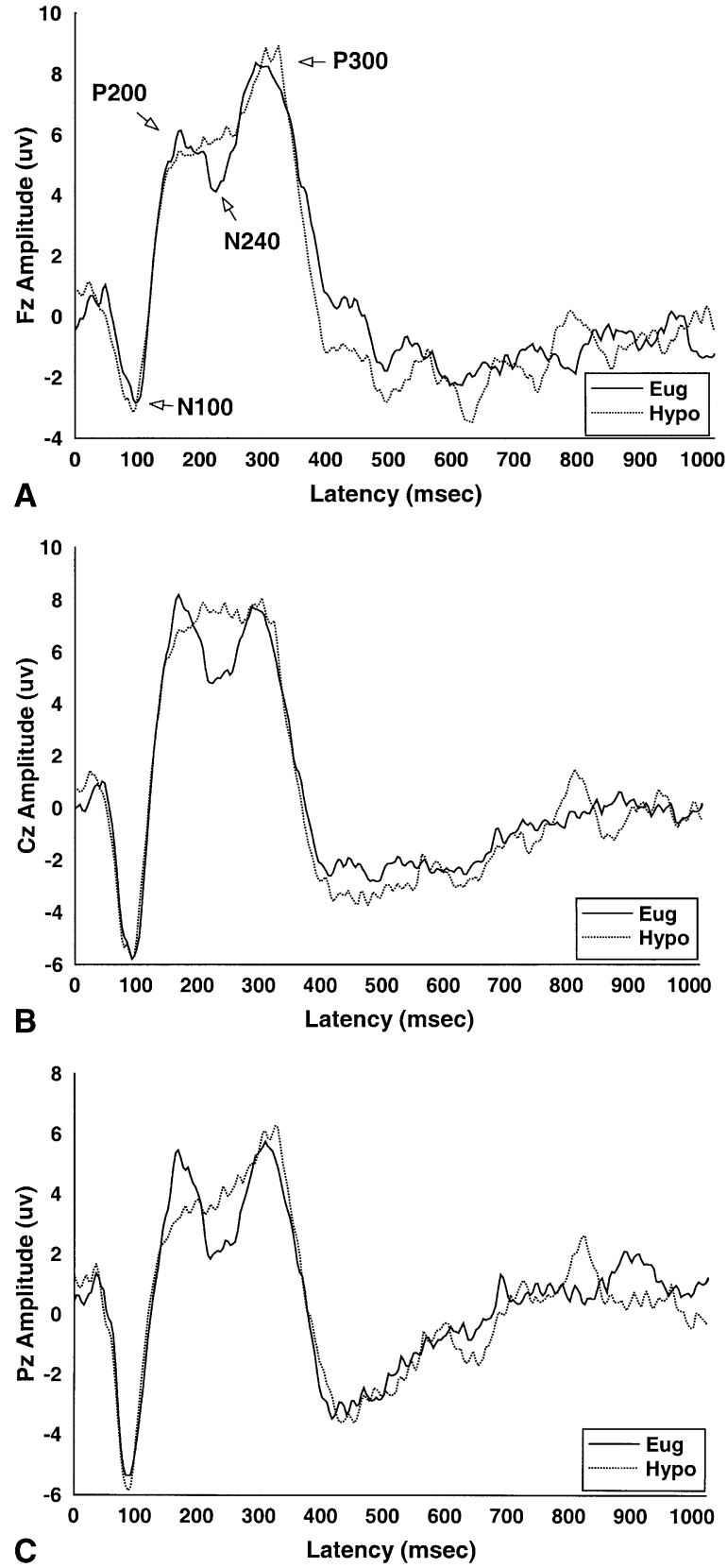

Fig. 1A-C. Grand average event-related potentials following the auditory 'odd-ball' stimulus recorded at the $\mathrm{Fz}(\mathbf{A}), \mathrm{Cz}(\mathbf{B})$ and $\mathrm{Pz}(\mathbf{C})$ electrode sites during the euglycaemia and hypoglycaemia study conditions. During hypoglycaemia, the N240 wave was lost, suggesting more continuous cerebral processing of the auditory stimuli. The amplitude and latency of the N100, P200 and P300 potentials were not affected

97.5 $\pm 7.1 \mathrm{msec}$ at the $\mathrm{Cz}$ and $\mathrm{Pz}$ electrodes respectively, but were shorter at $88.3 \pm 11.7 \mathrm{msec}(p=0.039)$ and $87.1 \pm 17.9 \mathrm{msec}(p=0.037)$ respectively in subjects who first underwent the hypoglycaemia clamp. No effects of order at the $\mathrm{Fz}$ electrode were observed for either N240 amplitudes or N100 latencies.

Symptoms. During the hypoglycaemia condition, increments occurred both in autonomic $(p<0.01)$ and neuroglycopenic symptom scores $(p<0.05)$ (Table 1$)$.
Table 2. Amplitudes of auditory event-related potentials during euglycaemia and hypoglycaemia

\begin{tabular}{lccc}
\hline & $\begin{array}{c}\text { Euglycaemia } \\
\text { condition }\end{array}$ & $\begin{array}{l}\text { Hypoglycaemia } \\
\text { condition }\end{array}$ & $p$ value \\
\hline $\mathrm{N} 100$ Amplitudes $(\mu \mathrm{v})$ & & \\
$F z$ & $-6.7 \pm 4.1$ & $-7.3 \pm 4.8$ & 0.438 \\
$C z$ & $-6.1 \pm 3.6$ & $-6.6 \pm 3.6$ & 0.689 \\
$P z$ & $-4.5 \pm 3.2$ & $-3.7 \pm 2.4$ & 0.236 \\
$\mathrm{P} 200$ Amplitudes $(\mu \mathrm{v})$ & & \\
$F z$ & $8.0 \pm 3.7$ & $7.7 \pm 2.7$ & 0.735 \\
$C z$ & $10.1 \pm 4.4$ & $10.9 \pm 5.6$ & 0.508 \\
$P z$ & $7.2 \pm 2.5$ & $7.6 \pm 3.9$ & 0.554 \\
$\mathrm{~N} 240$ Amplitudes $(\mu \mathrm{v})$ & & \\
$F z$ & $0.8 \pm 3.4$ & $1.0 \pm 2.8$ & 0.640 \\
$C z$ & $3.8 \pm 3.9$ & $4.0 \pm 3.9$ & $0.797 \mathrm{~b}$ \\
$P z$ & $3.3 \pm 3.7$ & $2.9 \pm 4.4$ & $0.805^{\mathrm{b}}$ \\
$\mathrm{P} 300$ Amplitudes $(\mu \mathrm{v})$ & & \\
$F z$ & $7.9 \pm 3.7$ & $7.0 \pm 3.5$ & 0.500 \\
$C z$ & $9.0 \pm 4.0$ & $8.5 \pm 3.7$ & 0.735 \\
$P z$ & $9.5 \pm 4.3$ & $8.9 \pm 4.0$ & 0.699 \\
\hline
\end{tabular}

${ }^{a} p$ values refer to the comparison between the study condition scores obtained during euglycaemia and hypoglycaemia

b The between-subjects effect of study 'order' was statistically significant

Results are presented from the study conditions of euglycaemia and hypoglycaemia

Values are means \pm SD

Tests of mental efficiency. Moderate hypoglycaemia resulted in a deterioration in performance of the Digit Symbol $(p<0.001)$ and Trail Making B tests $(p<0.01$; Table 1).

Tests of auditory information processing. The overall percentage correct scores for tests of basic auditory capabilities (determined by adding total scores for each sub-test to provide an overall percentage score for the test battery for each individual) at baseline were $81.6 \pm 7.8 \%$ on the euglycaemia study day and $81.8 \pm 6.9 \%$ during the hypoglycaemia study day. Overall percentage correct scores correlated highly between the two study conditions (Pearson's $r=0.91$; $p=0.000$ ). Thus, individual differences in auditory information processing were stable across time.

Acute hypoglycaemia caused a deterioration in auditory temporal processing, as evidenced by a reduced ability to discriminate the temporal order of two tones during hypoglycaemia ( $p=0.007$; Table 1$)$. Acute hypoglycaemia caused a deterioration in the performance of one of three tasks of simple auditory processing, single-tone loudness $(p=0.001$; Table 1), but had no effect on pitch discrimination and singletone duration (both $p>0.05$; Table 1 ).

The grand average of auditory event-related potentials from all 15 subjects during the study conditions of euglycaemia and hypoglycaemia are shown in Figure 1. 
Table 3. Latencies of auditory event-related potentials during euglycaemia and hypoglycaemia

\begin{tabular}{|c|c|c|c|}
\hline & $\begin{array}{l}\text { Euglycaemia } \\
\text { condition }\end{array}$ & $\begin{array}{l}\text { Hypoglycaemia } \\
\text { condition }\end{array}$ & $p$ value $^{\mathrm{a}}$ \\
\hline \multicolumn{4}{|c|}{ N100 Latencies (ms) } \\
\hline$F z$ & $95.7 \pm 18.4$ & $96.3 \pm 16.9$ & 0.917 \\
\hline$C z$ & $94.4 \pm 10.2$ & $92.8 \pm 12.8$ & $0.619^{b}$ \\
\hline$P z$ & $94.9 \pm 13.6$ & $90.4 \pm 14.6$ & $0.395^{\mathrm{b}}$ \\
\hline \multicolumn{4}{|c|}{ P200 Latencies (ms) } \\
\hline$F z$ & $171.5 \pm 27.2$ & $174.9 \pm 33.1$ & 0.814 \\
\hline$C z$ & $177.1 \pm 33.1$ & $173.1 \pm 33.3$ & 0.720 \\
\hline$P z$ & $173.3 \pm 33.2$ & $174.5 \pm 33.9$ & 0.902 \\
\hline \multicolumn{4}{|c|}{ N240 Latencies (ms) } \\
\hline$F z$ & $233.8 \pm 25.7$ & $231.4 \pm 35.1$ & 0.937 \\
\hline$C z$ & $243.5 \pm 31.2$ & $221.8 \pm 29.9$ & 0.012 \\
\hline$P z$ & $232.3 \pm 27.5$ & $229.2 \pm 39.3$ & 0.834 \\
\hline \multicolumn{4}{|c|}{ P300 Latencies (ms) } \\
\hline$F z$ & $307.7 \pm 24.3$ & $310.9 \pm 28.4$ & 0.556 \\
\hline$C z$ & $304.5 \pm 23.3$ & $305.1 \pm 22.7$ & 0.961 \\
\hline$P z$ & $307.2 \pm 30.3$ & $313.1 \pm 17.9$ & 0.535 \\
\hline
\end{tabular}

${ }^{a} p$ values refer to the comparison between the study condition scores obtained during euglycaemia and hypoglycaemia

b The between-subjects effect of study 'order' was statistically significant

Results are presented from the study conditions of euglycaemia and hypoglycaemia

Values are means \pm SD

During acute hypoglycaemia, no distinct N240 wave was observed between the P200 and P300 waveforms.

When the latencies and amplitudes of the individual components of the auditory event-related potentials from each subject were determined separately, acute hypoglycaemia had no effect on the mean latencies and amplitudes of the N100, P200 and P300 waves (all $p>0.05$; Tables 2 and 3). The latency of the N240 wave at the $\mathrm{Cz}$ electrode was reduced during hypoglycaemia ( $p=0.012$; Table 3$)$, but not at other electrode sites $(p>0.05$; Table 3$)$. The amplitude of the N240 wave was not affected by acute hypoglycaemia ( $p>0.05$; Table 2).

\section{Discussion}

In our study, acute hypoglycaemia caused a significant disruption in auditory temporal processing and in a single aspect of 'simple' auditory discrimination (the ability to distinguish the louder of two auditory tones) in adults with Type I diabetes who had moderate to poor glycaemic control. These data are consistent with the results of a previous study from our centre of auditory information processing during acute hypoglycaemia in non-diabetic subjects [4].

Other aspects of 'simple' auditory discrimination, namely the ability to discriminate tone duration and pitch, were not affected by hypoglycaemia either in this study or in a previous study [4]. This could indicate that these abilities have an innate resistance to the effects of neuroglycopenia, but could also be related to differences in the glycaemic thresholds at which the performance of these tests becomes impaired. The thresholds for impairment of other cognitive tasks are recognised to differ during acute hypoglycaemia. For example, simple tasks such as finger tapping are often not affected until blood glucose concentrations decline to below $2.0 \mathrm{mmol} \cdot \mathrm{l}^{-1}$ [29], while the performance of more complex tasks such as four-choice reaction time become impaired when blood glucose concentrations decrease below approximately $3.2 \mathrm{mmol} \cdot \mathrm{l}^{-1}$ [30]. Thus, it is conceivable that, to impair all aspects of 'simple' auditory discrimination, blood glucose concentrations would have had to be substantially lower than those attained in our study.

The Test of Basic Auditory Capabilities (TBAC) has been used extensively to study auditory function, particularly to explore the associations between auditory perception and reading disabilities [27]. Performance of the TBAC is not affected by mid-frequency or high-frequency hearing loss and both its psychometric properties and its test-retest reliability have been established in normal and elderly, hearing-impaired subjects [26]. The TBAC uses tones of up to $250 \mathrm{msec}$, as a consequence of which it provides a measure of 'short auditory storage', i.e. the initial recognition of the auditory stimulus before further analysis and retention takes place [31]. The TBAC also uses information processing tasks which, by manipulating the duration of the stimulus, provide an index of the speed at which subjects are able to process auditory input. Thus, our results suggest that acute hypoglycaemia disrupts short auditory storage and slows the speed at which the brain is able to process information obtained by hearing (at the experimental or psychophysical level).

The relation between individual differences in cognitive performance and measures of the speed of information processing has been subjected to considerable scientific scrutiny. Significant correlations exist between traditional psychometric measures of intelligence and visual inspection time, simple and choice reaction time, speed of scanning information in shortterm memory, speed of retrieval of information from long-term memory and auditory information processing $[32,33,34,35,36,37,38,39]$. The scores achieved on each of the four subtests of the TBAC correlate with performance on the mathematical section of the Scholastic Aptitude Test [40, 41]. It is conceivable, therefore, that acute hypoglycaemia actually impairs higher cognitive functions through its deleterious effects on basic information processing, rather than through its effects on the higher processes themselves. Indeed, this hypothesis may not be confined to the effects of acute hypoglycaemia, since speed of in- 
formation processing can also have a central role in age-related changes in cognitive function [42]. The auditory (TBAC) and visual information (visual inspection time, visual change detection and visual movement detection) processing data from our laboratory $[2,3,4]$ suggest that temporal order processing could be one such basic function which has deleterious effects on many high-level cognitive abilities. Confirmation of this general hypothesis would, however, require a much larger study examining the effects of acute hypoglycaemia on higher cognitive functions (such as psychometric aspects of intelligence), after adjustment of scores for the effect of poorer information processing. The underlying neu$\mathrm{ral} /$ biological basis of temporal order processing is not well established, but is an area of active research [43].

In the present study, acute hypoglycaemia had no effect on the amplitude and latency of P300 components of the AERPs in response to an 'oddball' task. This is in contrast to previous findings showing that the latency of the auditory P300 wave was prolonged at an arterialised blood glucose concentration of $2.5 \mathrm{mmol} \cdot \mathrm{l}^{-1}$ in ten subjects with Type I diabetes with strict glycaemic control (mean $\mathrm{HbA}_{1 \mathrm{c}} 6.9 \%$ ) [8]. However, other studies in adult subjects with Type I diabetes have suggested that the quality of preceding glycaemic control has a major influence on the blood glucose threshold at which auditory P300 amplitudes and latencies are affected. Thus, if subjects have strict glycaemic control, a much lower blood glucose is required to affect the P300 wave [44, 45]. Indeed, in one study in which the mean $\mathrm{HbA}_{1 \mathrm{c}}$ of the subjects was $8.1 \%$ (only $0.7 \%$ lower than the mean $\mathrm{HbA}_{1 \mathrm{c}}$ of the subjects participating in our study), P300 latencies were not affected when venous blood glucose concentrations were as low as $1.8 \mathrm{mmol} \cdot \mathrm{l}^{-1}$ [46]. Thus, although it is recognised that acute hypoglycaemia can have deleterious effects on the P300 component of AERPs, it seems likely that in our study the depth of hypoglycaemia might not have been sufficient to reach the threshold at which impairment occurs.

The impact of acute hypoglycaemia on the earlier components of the AERP waveform has not been studied previously in people with Type I diabetes. In one study of non-diabetic subjects [14], the amplitudes of the N100 waves, after non-target tones, were reduced during acute hypoglycaemia (arterialised capillary plasma glucose concentration $2.65 \mathrm{mmol} \cdot \mathrm{l}^{-1}$ ), although the amplitude of the P200 component and the latencies of the N100 and P200 waves were not affected. In another study of non-diabetic subjects [10], mild hypoglycaemia (whole blood glucose concentration $3.2 \mathrm{mmol} \cdot \mathrm{l}^{-1}$ ) reduced the amplitude of the 'N2' component (a trough occurring at approximately $200 \mathrm{msec}$ and analogous to the N240 wave described in the present study) of the AERP occurring after target tones in a complex auditory task that included 'novel' auditory stimuli (e.g. a dog's bark and sound- ing a car horn) as well as the conventional non-target and 'oddball' tones. This observation is of course consistent with the loss of the N240 wave, as we observed in the grand-average AERP waveforms during hypoglycaemia. The precise biological and cognitive correlate of this wave has not been established, but the amplitude of the N2/N240 wave increases as auditory target discrimination is made more difficult by approximating the pitch of target and non-target tones [47].

The N240 amplitude and latency data which were extracted from the individual subject AERP waveforms rather than from 'averaged' waveforms from all 15 subjects, are included for completeness but are of much more limited validity than the N100, P200 and P300 data. Strict criteria were used to define the precise location of the N240 wave for each subject during the two study conditions. However, individual subject AERP waveforms showed considerable variability and it was often very difficult to identify a clear N240 wave from the background electrical 'noise', particularly during hypoglycaemia. Therefore, the apparent reduction in N240 wave latency at the $\mathrm{Cz}$ electrode during hypoglycaemia and the failure to observe any reduction in N240 amplitudes during hypoglycaemia could reflect the inadequacy of the criteria used to define the waveform. In contrast, N100, P200 and P300 waves were more readily identifiable and, as a consequence, the latency and amplitude data reported are robust. The effects of study order on N100 latencies and N240 amplitudes have no plausible biological basis and are likely to represent type 1 statistical errors.

In conclusion, we have shown that moderate hypoglycaemia in people with Type I diabetes not only provoked higher cortical decrements, but also caused disruption of basic processing of auditory information. While the clinical relevance of these findings has yet to be established, adequate hearing is clearly crucial for normal language and in the successful performance of many aspects of routine daily living. The demonstration of significant changes in auditory discrimination during hypoglycaemia could, therefore, have important implications for people with insulin-treated diabetes. The data also re-affirm the need to study lowlevel and high-level cognitive processing during acute hypoglycaemia, so that the basic processes that contribute to cognitive dysfunction can be elucidated.

Acknowledgements. M.W.J. Strachan and R.J. McCrimmon were supported by a research grant from Eli Lilly and FMEE by a research grant from Novo Nordisk Pharmaceuticals. I.J. Deary is the recipient of a Royal Society-Wolfson Research Merit Award.

\section{References}

1. Deary IJ (1993) Effects of hypoglycaemia on cognitive function. In: Frier BM, Fisher BM (eds) Hypoglycaemia and diabetes: clinical and physiological aspects. Edward Arnold, London, pp 80-92 
2. McCrimmon RJ, Deary IJ, Huntly BJH, MacLeod KJM, Frier BM (1996) Visual information processing during controlled hypoglycaemia in humans. Brain 119: 1277-1287

3. Ewing FME, Deary IJ, McCrimmon RJ, Strachan MWJ, Frier BM (1998) Effect of acute hypoglycemia on visual information processing in adults with Type 1 diabetes mellitus. Physiol Behav 64: 653-660

4. McCrimmon RJ, Deary IJ, Frier BM (1997) Auditory information processing during acute insulin-induced hypoglycaemia in non-diabetic human subjects. Neuropsychologia 35 : $1547-1533$

5. Jones TW, McCarthy G, Tamborlane WV et al. (1990) Mild hypoglycemia and impairment of brain stem and cortical evoked potentials in healthy subjects. Diabetes 39: 1550-1555

6. Ziegler D, Hubinger A, Gries FA (1991) Changes in brainstem auditory evoked potentials during insulin-induced hypoglycaemia in type I diabetic patients. Diabet Med 8: 805-811

7. Lingenfelser T, Buettner UW, Sommerwerck U, Renn W, Eggstein M, Jakober B (1993) Neurophysiological impairments in IDDM patients during euglycemia and hypoglycemia. Diabetes Care 16: 1438-1445

8. King P, Kong M-F, Parkin H, Macdonald IA, Barber C, Tattersall RB (1998) Intravenous lactate prevents cerebral dysfunction during hypoglycaemia in insulin-dependent diabetes mellitus. Clin Sci (Colch) 94: 157-163

9. Regan D (1989) Human brain electrophysiology: evoked potentials and evoked magnetic fields in science and medicine. Elsevier, New York

10. Münte TF, Berger D, Terkamp C, Schöfl C, Johannes S, Brabant G (1995) Cognitive functioning in experimental hypoglycaemia assessed with event-related potentials. Neuroreport 6: 1509-1512

11. Lindgren M, Eckert B, Stenberg G, Agardh C-D (1996) Restitution of neurophysiological functions, performance, and subjective symptoms after moderate hypoglycaemia in non-diabetic humans. Diabet Med 13: 218-225

12. De Feo P, Gallai V, Mazzotta G et al. (1988) Modest decrements in plasma glucose concentration cause early impairment in cognitive function and later activation of glucose counterregulation in the absence of hypoglycemic symptoms in normal man. J Clin Invest 82: 436-444

13. Blackman JD, Towle VL, Lewis GF, Spire J-P, Polonsky KS (1990) Hypoglycemic thresholds for cognitive dysfunction in humans. Diabetes 39: 828-835

14. Kern W, Lieb K, Kerner W, Born J, Fehm HL (1990) Differential effects of human and pork insulin-induced hypoglycemia on neuronal functions in humans. Diabetes 39: 1091-1098

15. Kerr D, Diamond MP, Tamborlane WV, Kerr S, Sherwin RS (1993) Influence of counterregulatory hormones, independently of hypoglycaemia, on cognitive function, warning symptoms and glucose kinetics. Clin Sci (Colch) 85: 197-202

16. Thomas M, Sherwin RS, Murphy J, Kerr D (1997) Importance of cerebral blood flow to the recognition of and physiological responses to hypoglycemia. Diabetes 46: 829-833

17. Fanelli CG, Paramore DS, Hershey T et al. (1998) Impact of nocturnal hypoglycemia on hypoglycemic cognitive dysfunction in type 1 diabetes. Diabetes 47: 1920-1927

18. Ovalle F, Fanelli CG, Paramore DS, Hershey T, Craft S, Cryer PE (1998) Brief twice-weekly episodes of hypoglycemia reduce detection of clinical hypoglycemia in Type 1 diabetes mellitus. Diabetes 47: 1472-1479

19. Nelson HE, Willison JR (1991) National Adult Reading Test (NART) Test Manual, 2nd edn. NFER-Nelson, Windsor
20. Heim AW, Watts KP, Simmonds V (1975) Alice Heim 4 Question Book, 2nd edn. NFER-Nelson, Windsor

21. De Fronzo RA, Tobin JD, Andres R (1979) Glucose clamp technique: a method for quantifying insulin secretion and resistance. Am J Physiol 237: E214-E233

22. Deary IJ, Hepburn DA, MacLeod KM, Frier BM (1993) Partitioning the symptoms of hypoglycaemia using multisample confirmatory factor analysis. Diabetologia 36: 771777

23. Wechsler D (1981) Manual of the Wechsler Adult Intelligence Scale - Revised. The Psychological Corporation Limited, New York

24. Reitan RM, Davison LA (1974) Clinical neuropyschology: current status and applications. Hemisphere, New York

25. Watson CS, Johnson DM, Lehman JR, Kelly WJ, Jensen JK (1982) An auditory discrimination test battery. J Acoust Soc Am 71[Suppl 1]: S73 [Abstract]

26. Christopherson LA, Humews LE (1992) Some psychometric properties of the Test of Basic Auditory Capabilities. J Speech Hear Res 35: 929-935

27. Watson BU, Miller TK (1993) Auditory perception, phonological processing, and reading ability/disability. J Speech Hear Res 36: 850-863

28. Jasper HH (1958) The ten-twenty electrode system of the International Federation. Electroencephalogr Clin Neurophysiol 10: 371-375

29. Pramming S, Thorsteinsson B, Theilgaard A, Pinner EM, Binder C (1986) Cognitive function during hypoglycaemia in type 1 diabetes mellitus. BMJ 292: 647-650

30. Heller SR, Macdonald IA (1996) The measurement of cognitive function during acute hypoglycaemia: experimental limitations and their effect on the study of hypoglycaemia unawareness. Diabet Med 13: 607-615

31. Cowan N (1984) On short and long auditory stores. Psychol Bull 96: 341-370

32. Raz N, Willerman L, Ingmunson P, Hanlon M (1983) Aptitude-related differences in auditory recognition masking. Intelligence 7: 71-90

33. Vernon PA (1983) Speed of information processing and general intelligence. Intelligence 7: 53-70

34. Raz N, Willerman L, Yama M (1987) On sense and senses: Intelligence and auditory information processing. Pers Individ Dif 8: 201-210

35. Eysenck MJ (1988) The concept of "intelligence": Useful or useless? Intelligence 12: 1-16

36. Deary IJ (1994) Intelligence and auditory discrimination: separating processing speed and fidelity of stimulus representation. Intelligence 18: 189-213

37. Deary IJ (1994) Sensory discrimination and intelligence: postmortem or resurrection? Am J Psychiol 107: 95-115

38. Deary IJ (1995) Auditory inspection time and intelligence: what is the direction of causation? Dev Psychol 31: 237250

39. Deary IJ, Stough C (1996) Intelligence and inspection time: achievements, prospects and problems. Am Psychol 51: 599-608

40. Watson BU (1991) Some relationships between intelligence and auditory discrimination. J Speech Hear Res 34: 621-627

41. Watson BU (1992) Auditory temporal acuity in normally achieving and learning-disabled college students. J Speech Hear Res 35: 148-156

42. Salthouse TA (2000) Aging and measures of processing speed. Biol Psychol 54: 35-54

43. Deary IJ, Simonotto E, Marshall A et al. (2001) The functional anatomy of inspection time: a pilot fMRI study. Intelligence 29: 497-510 
44. Ziegler D, Hubinger A, Muhlen H, Gries FA (1992) Effects of previous glycaemic control on the onset and magnitude of cognitive dysfunction during hypoglycaemia in Type I (insulin-dependent) diabetic patients. Diabetologia 35: 828834

45. Jones TW, Borg WP, Borg MA et al. (1997) Resistance to neuroglycopenia: an adaptative response during intensive insulin treatment of diabetes. J Clin Endocrinol Metab 82: $1713-1718$
46. Tallroth G, Lindgren M, Stenberg G, Rosen I, Agardh C-D (1990) Neurophysiological changes during insulin-induced hypoglycaemia and in the recovery period following glucose infusion in Type I (insulin-dependent) diabetes mellitus and in normal man. Diabetologia 33: 319-323

47. Fitzgerald PG, Picton TW (1983) Event-related potentials recorded during the discrimination of improbable stimuli. Biol Psychol 17: 241-276 